\title{
Risk analysis and safety in LPG storage: the Indexed Method
}

\author{
M. Mariani \& M. R. Vallerotonda \\ ISPESL (Italian Authority for Health and Safety at Work), \\ DIPIA (Department of Production Plants and Human Settlements), \\ Rome, Italy
}

\begin{abstract}
The major-accident hazards industries involving dangerous substances are subjected to European Council Directive 96/82. In according with Seveso's norms the operator must produce the "Safety Report" (SR) in which he must demonstrate that all necessary measures are taken in order to prevent such accidents.

The essential purpose of the Indexed Method is to find, through a numerical classification, the technological units of plant that are probable accident sources. In this way the operator aims to implementation the most appropriate prevention and protection measures in order to reduce the major-accident hazards.

In Annex A of the present paper the application of the Indexed Method to an underground tank stocking liquefied petroleum gas (LPG) is described.
\end{abstract}

Keywords: major-accident hazards, dangerous substances, Indexed Method.

\section{Introduction}

The European Council Directive 82/501 (Seveso I) was adopted for majoraccident hazards of certain industrial activities involving dangerous substances.

The above Directive was reviewed in the light of industrial accidents, studies on carcinogens and substances dangerous to the environment and, so, in Italy the Law No. 334/99 was issued (Seveso II). 


\section{Safety report}

Article 8 of Italian Law 334/99 requires the operator to produce a Safety Report (SR) in order to achieve high protection levels for workers, human health and the environment by appropriate measures, structures and management systems.

So, in the SR the operator must list:

- the lay-out of the establishment (i.e. main storage facilities, process installations) and the description of the main activities from the point of view of safety;

- presentation of the environment of the establishment (description of the site including the geographical location, meteorological, geological, hydrographical conditions and, if necessary, its history);

- description of the handled substances, their types and quantities (i.e. origin of the substance; toxicological, flammability and explosive, physical and chemical characteristics) and identification of their hazards;

- $\quad$ an adequate description of intrinsic hazard activities, services and technical equipment for safe operation;

- identification and accidental risk analysis and prevention methods;

- internal emergency plans;

- measures of protection and intervention to limit the consequences of an accident;

- the supply of information to the Competent Authority for the preparation of external emergency plans.

\subsection{Risk analysis}

The operator must identify all possible sources of major risks for the top tier establishment in order to produce the risk analysis report.

A table listing the identified major-accidents, their likelihood and consequences for man and the environment is also required.

For this purpose, the methods that might be used are various and each of them has its own strengths and weaknesses for identifying failures. So, one method alone may be insufficient to identify human/management errors and procedural/hardware failures.

The risk analysis report includes:

- detailed description of the possible major-accident scenarios and their probability;

- $\quad$ assessment of the extent and severity of the consequences showing areas liable to be affected by such accidents;

- description of technical parameters and equipment used for the safety of technological installations.

The operator needs to determine the most "critical units" inside the plant before using the risk analysis method, therefore, he can use the Indexed Method (IM). 


\section{$3 \quad$ LPG storage and land-use planning}

LPG is a highly flammable substance that, under certain conditions, could fire and explode. The Italian Law 334/99 requires that for LPG storages, when it exceeds 50 tonnes at any one time, the operator must produce the SR (Italian Law 15/05/1996 "Criteri di analisi e valutazione dei Rapporti di Sicurezza relativi ai depositi di GPL").

The management system of LPG storage is simple, because there is only closed loop handling of LPG. Generally, the number of involved workers is small. The LPG storages were analysed for these two characteristics.

It is also important to note the correlation between the IM results and the land-use planning (Italian Law 09/05/2001 "Requisiti minimi di sicurezza in materia di pianificazione urbanistica e territoriale per le zone interessate da stabilimenti a rischio di incidente rilevante").

Note that the IM doesn't give the accident probabilities, but it gives the categorization of the LGP storage.

In other words, the categorisation takes into account the extent and severity of the consequences toward the surrounding areas. In the Italian framework there are four categories: A, B, C, D.

Category A is the best case, the last, D, is the worst case.

In addiction, the storage category takes into account the existing urban context and its future development.

All this improves an industrial development and, at the same time, ensures the conditions for suitable territorial balance.

\section{Indexed Method}

The IM is used in order to identify the factors that define the cost and the technical performances. The criticality of the plant units depends on productivity, but overall on safety at work and environmental hazards.

The IM is a qualitative risk analysis and it is also a start-point for a more detailed quantitative risk analysis.

A technological unit can be a component or a system of the plant. It is defined as critical when its failure involves environmental quality and human health.

The criticality level of a unit is given by multiplication of the index factors taken from experience or scheduled in technical literature. Each of these takes account of the environmental safety, the reliability and the maintenance of the components.

\subsection{Indexed Method phases}

There are two phases of the IM:

- I: Evaluation of intrinsic indices;

- II: Determination of adjusted indices.

It is possible that one unit can be characterized by a double risk degree: the first concerning the safety of the plant and the second concerning the 
toxicological level for the environment. The most critical of the two aspects will obviously be considered.

\subsubsection{Phase I: evaluation of intrinsic indices}

Phase I is composed of the following steps:

A) Logical units: the plant is divided into technological units that are identified by temperature/pressure level and by contained substance.

B) Main substance: is the substance/compound that provides the greatest potential energy in case of release from fire, explosion or exothermic reaction.

C) Material Factor (B): is the intrinsic rate of potential energy release.

D) Penalty Factors:

- M Factor - Specific risks substances: linked to specific risks of substances that can influence the nature of an accident (fire or explosion).

- P Factor - General risks process: accounts for the risks associated with the basic process and other industrial transactions.

- S Factor - Special risks process: accounts for high pressure (p), low temperature, high temperature, risks corrosion, losses by joints, vibration risks and cyclic loads, operation under flashpoint, electrostatic risks, risks resulting from intensive use.

- Q Factor - Risks for quantity substance: accounts for the risks associated to quantities of combustible, flammable or explosive materials used. The total amount ( $\mathrm{K}$, in tonnes) is calculated including the content in pipes and tanks.

- L Factor - Lay-out risks: the risk is related to height (H, meters), work area ( $\mathrm{N}$, square meters), domino effects, structure design, soil conformation, surface drainage.

- s Factor - Risks for human health: accounts for the toxicity of substances evaluating the effects caused in case of accident.

E) Indices risks

- F: Fire index

This is determined by the potential energy released from LPG present in the logical unit:

- C: Explosion confined index

$$
\mathrm{F}=\mathrm{B} \times[\mathrm{K} /(\mathrm{N} \times 1000)]
$$

This provides a measure of the potential for explosion inside the logical unit. It is determined by the expression:

$$
\mathrm{C}=1+[(\mathrm{M}+\mathrm{P}+\mathrm{S}) / 100]
$$

\section{- A: Explosion in air index}

This is determined relatively to the amount of LPG present in the logical unit and the characteristics of gas and release (share and conditions of release).

$$
\mathrm{A}=\mathrm{B} \times(1+\mathrm{p}) \times(\mathrm{Q} \times \mathrm{H} \times \mathrm{C} / 1000) \times(\mathrm{t}+273) / 300
$$

$\mathrm{t}$ is the maximum temperature of the logical unit.

- G: General risk index

This is obtained by a combination of the explosion index (D) and the above indices $(\mathrm{C}, \mathrm{A}, \mathrm{F})$. 


$$
\begin{gathered}
\mathrm{D}=\mathrm{B} \times[(1+\mathrm{M} / 100)] \times[(1+\mathrm{P} / 100)] \times[1+(\mathrm{S}+\mathrm{Q}+\mathrm{L}+\mathrm{s}) / 100] \\
\mathrm{G}=\mathrm{D} \times\left[1+0,2 \times \mathrm{C} \times(\mathrm{A} \times \mathrm{F})^{1 / 2}\right]
\end{gathered}
$$

The results are compared with the value ranges showed in Table 1:

Table 1: $\quad$ Category indices.

\begin{tabular}{|l|l|l|l|l|l|}
\hline Category & G (general) & $\begin{array}{l}\text { T } \\
\text { (toxic) }\end{array}$ & F (fire) & \multicolumn{2}{|c|}{ Outbreak } \\
\hline & & & & A (in air) & C(confined) \\
\hline High Light & $0-20$ & $0-5$ & $0-2$ & $1-10$ & $0-1,5$ \\
\hline Low & $20-100$ & $5-10$ & $2-5$ & $10-30$ & $1,5-2,5$ \\
\hline Moderated & $100-500$ & $10-15$ & $5-10$ & $30-100$ & $2,5-4$ \\
\hline High I & $500-1100$ & $15-20$ & $10-20$ & $100-400$ & $4-6$ \\
\hline High II & $1100-2500$ & - & $20-50$ & - & - \\
\hline A lot High & $2500-$ & 20 & $50-100$ & $400-$ & 6 \\
& 12500 & & & 1700 & \\
\hline Serius & $12500-$ & - & $100-$ & 1700 & - \\
& 65000 & & 250 & & - \\
\hline Most serious & 65000 & - & 250 & - & \\
\hline
\end{tabular}

\subsubsection{Phase II: determination of adjusted indices}

In phase II all the safety measures of the logical unit are considered because they reduce the number and the gravity of accidents.

This phase is composed of the following steps:

\section{A) Adjusted factors}

$\checkmark \quad \mathrm{K}_{1}=$ containment factor

This factor accounts for pressure equipment, pipelines transfer, containment systems, emergency discharges.

$$
\checkmark \quad \mathrm{K}_{2}=\text { process control factor }
$$

This factor accounts for alarm and block systems, centralized controls, operating instructions, supervision of the plant.

$$
\checkmark \quad \mathrm{K}_{3}=\text { safety factor }
$$

This factor accounts for safety management, safety training and procedures for maintenance and security of the plant.

$$
\checkmark \quad \mathrm{K}_{4}=\text { fire equipment factor }
$$

This factor accounts for structures, barriers and fire equipments.

$$
\checkmark \quad \mathrm{K}_{5}=\text { isolation and elimination substances factor }
$$

This factor accounts for drainage systems, valve systems, ventilation and dilution.

$\checkmark \quad \mathrm{K}_{6}=$ fire operations factor

This factor accounts for fire alarms, fixed extinction equipment, portable fire equipment, support for fire, cooperation in the establishment. 
B) Adjusted risk indices

- Fire adjusted index

- Explosion confined adjusted index

$\mathrm{F}^{\prime}=\mathrm{F} \times\left(\mathrm{K}_{1} \times \mathrm{K}_{3} \times \mathrm{K}_{5} \times \mathrm{K}_{6}\right)$

- Explosion in air adjusted index

$\mathrm{C}^{\prime}=\mathrm{C} \times\left(\mathrm{K}_{2} \times \mathrm{K}_{3}\right)$

- General risk adjusted index

$\mathrm{A}^{\prime}=\mathrm{A} \times\left(\mathrm{K}_{1} \times \mathrm{K}_{2} \times \mathrm{K}_{3} \times \mathrm{K}_{5}\right)$

$\mathrm{G}^{\prime}=\mathrm{G} \times\left(\mathrm{K}_{1} \times \mathrm{K}_{2} \times \mathrm{K}_{3} \times \mathrm{K}_{4} \times \mathrm{K}_{5} \times \mathrm{K}_{6}\right)$

The comparison among intrinsic and adjusted indices leads to finding the most critical logical unit plant and the criticality nature in respect of fire or explosion risk. At the same time it is possible to evaluate the reduction of the hazards through the utilisation of active and passive systems applied to the logical unit plant.

\subsection{LPG storage: categorisation and environmental compatibility}

The categorisation of logical units is important because it compares the general risk indices $G^{\prime}$ with the value ranges of table 2 :

Table 2: $\quad$ Logical unit category.

\begin{tabular}{|l|c|}
\hline General risk index & Category \\
\hline $0-100$ & $\mathrm{~A}$ \\
\hline $101-110$ & $\mathrm{~B}$ \\
\hline $1101-12500$ & $\mathrm{C}$ \\
\hline$>12500$ & $\mathrm{D}$ \\
\hline
\end{tabular}

The logical unit is associated to a category (in letter), which represents the hazardous situation connected to the adjusted risk.

It is important that all prevention and protection measures must lead the critical unit almost to the B category.

\section{Conclusions}

The present work shows that the IM is a tool for pre-conceptual risk analysis and it allows a suitable land-use planning to be defined.

At the same time, the IM gives the risk type (fire or explosion) of the logical unit. This information is necessary in order to improve the prevention and protection measures for human health and safeguard the environment in function of the specific risk.

\section{Annex A}

The IM is applied to an LPG underground tank. The numerical used values are taken from a real Safety Report of LPG storage.

$\mathrm{B}=21,00$

$\mathrm{P}($ pressure $)=18 \mathrm{bar}$

$\mathrm{t}=50^{\circ} \mathrm{C}$ 


\section{A.1 Evaluation of intrinsic indices}

\section{- Penalty factors:}

- M Factor: by default for LGP storage

$$
\mathrm{M}=30
$$

- P Factor:

- handling: for storage $=10$;

- transportable containers: for underground tanks $=0$;

- transferring of substances: there are only closed pipes $=25$.

$$
\mathrm{P}=(10+0+25)=35
$$

- S Factor:

- high pressure (p): it is 115 because the main substance is propane and it is in an underground tank;

- low temperature: for steel $=15$;

- high temperature: by default for LGP storage $=25$;

- corrosion risks: LPG is not aggressive towards metals $=20$;

- losses by joints: because of design and materials used $=10$;

- vibration risks and cyclic loads: for storage $=10$;

- operation under flashpoint: for underground tanks $=0$;

- explosion risk above average: by default $=40$;

- electrostatic risks: for propane by default $=30$;

- intensive use risk: in according with the assessments $=25$.

$$
\mathrm{S}=(115+15+25+20+10+10+0+40+30+25)=290
$$

- Q Factor: the total amount (K) (in tonnes) in this case is 6.000 tonnes of LPG.

- L Factor:

$$
\mathrm{Q}=280
$$

- height $(\mathrm{H})$ : for tanks $\mathrm{H}=0,50$.

- work area $(\mathrm{N})$ : (in square meters) $\mathrm{N}=23$.

- domino effects: the distance between the storage units $=10$.

- structure design: for its design $=280$.

- soil conformation: the distance between wells is within 10-20 $\mathrm{m}=20$.

- surface drainage: there is no flooring for the drainage $=100$.

- other features: for logical units not equipped with two front access roads for fire operations $=75$.

$$
\mathrm{L}=(0,50+23+10+280+20+100+75)=509
$$

- s Factor: this accounts for the toxicity of substances evaluating the effects caused in case of accident.

\section{A.1.2 Indices risks}

- Fire index:

$$
\mathrm{F}=\mathrm{B} \times[\mathrm{K} /(\mathrm{N} \times 1000)]=5.478,26
$$

- Explosion confined index:

$$
\mathrm{C}=1+[(\mathrm{M}+\mathrm{P}+\mathrm{S}) / 100]=4,55
$$

- Explosion in air index:

$$
\mathrm{A}=\mathrm{B} \times(1+\mathrm{p}) \times(\mathrm{Q} \times \mathrm{H} \times \mathrm{C} / 1000) \times(\mathrm{t}+273) / 300=522,21
$$


- General risk index:

$$
\mathrm{G}=\mathrm{D} \times\left[1+0,2 \times \mathrm{C} \times(\mathrm{A} \times \mathrm{F})^{1 / 2}\right]=668.949,26
$$

where

$$
\mathrm{D}=\mathrm{B} \times[(1+\mathrm{M} / 100)] \times[(1+\mathrm{P} / 100)] \times[1+(\mathrm{S}+\mathrm{Q}+\mathrm{L}+\mathrm{s}) / 100]=434,34
$$

These results are compared with the value ranges of Table 1.

It appears that the fire index, F, and the explosion confined index, $\mathrm{C}$, are to be taken into account because they have a very high values.

\section{A.2 Determination of adjusted indices}

\section{- Adjusted factors:}

Each adjusted factor is given by the product of individual under-multiple factors.

$$
\checkmark \quad \mathrm{K}_{1}=\text { Containment factor } \quad(0,53 \times 0,66 \times 0,90 \times 0,95 \times 0,85)=0,26
$$

This factor accounts for:

- pressure equipment: $=0,53$ because there are two valves;

- pipelines transfer: the pipelines are well constructed $=0,66$;

- system containment: in the case of underground tanks by default $=0,90$;

- detection system losses: $=0,95$ because there are gas detectors;

- emergency discharges: each tank has safety valves $=0,85$.

$$
\checkmark \quad \mathrm{K}_{2}=\text { Process control factor } \quad(0,76 \times 0,90 \times 1 \times 0,95)=0,65
$$

This factor accounts for:

- alarm and block systems: the main handling systems are intercepted $=0,76$;

- centralized control: $=0,90$ because there is a centralized management;

- operating instructions: $=1$ because there are adequate emergency procedures;

- plant supervision: it is regular $=0,95$.

$$
\checkmark \quad \mathrm{K}_{3}=\text { Safety factor }
$$$$
(0,85 \times 0,90 \times 0,90)=0,69
$$

This factor accounts for:

- safety management: $=0,85$ because the company performs regular checks;

- safety training: $=0,90$ because there is a regular programme of training and courses for the safety of workers;

- maintenance and security procedures: the maintenance and inspections are performed as documented in specific programmes $=0,90$.

$$
\checkmark \quad \mathrm{K}_{4}=\text { Fire equipment factor } \quad(0,50 \times 0,80 \times 0,90)=0,36
$$

This factor accounts for:

- protective structures: for underground tanks is adopted by default $=0,50$;

- barriers: the unit transfer has been carried out to resist explosion $=0,80$;

- fire protection equipment: $=0,90$ because the spraying system is automatically activated.

$\checkmark \quad \mathrm{K}_{5}=$ Isolation and delimitation substances factor

This factor accounts for:

$(0,85 \times 0,70 \times 0,90)=0,54$

- drainage systems: the area under the tank is waterproof and compact $=0,85$; 
- valve system: there is a system for pumping water therefore $=0,70$;

- ventilation and dilution: $=0,90$ because the gas detection device is properly calibrated.

$$
\checkmark \quad K_{6}=\text { Fire operations factor } \quad(0,90 \times 1 \times 0,90 \times 0,90 \times 0,90)=0,66
$$

This factor accounts for:

- fire alarms: $=0,90$ because the network of fire detection is connected directly to the permanent presidium;

- fixed extinction equipment: is present including cooling systems $=1$;

- portable fire equipment: availability of portable fire equipment is adequate $=$ 0,90 ;

- fire support: there are firefighters locally $=0,90$;

- establishment cooperation: there is a training programme for workers about using fire-fighting equipment $=0,90$.

\section{A.2.1 Adjusted risk indices}

- $\quad$ Fire adjusted index

$$
\begin{aligned}
\mathrm{F}^{\prime}=\mathrm{F} \times\left(\mathrm{K}_{1} \times \mathrm{K}_{3} \times \mathrm{K}_{5} \times \mathrm{K}_{6}\right) & =340,72 \\
\mathrm{C}^{\prime}=\mathrm{C} \times\left(\mathrm{K}_{2} \times \mathrm{K}_{3}\right) & =2,04
\end{aligned}
$$

- Explosion in air adjusted index

$$
\mathrm{A}^{\prime}=\mathrm{A} \times\left(\mathrm{K}_{1} \times \mathrm{K}_{2} \times \mathrm{K}_{3} \times \mathrm{K}_{5}\right)=32,17
$$

- General risk adjusted index $\mathrm{G}^{\prime}=\mathrm{G} \times\left(\mathrm{K}_{1} \times \mathrm{K}_{2} \times \mathrm{K}_{3} \times \mathrm{K}_{4} \times \mathrm{K}_{5} \times \mathrm{K}_{6}\right)=9.732,568$

Table 3 shows the comparison among intrinsic and adjusted indices.

Table 3.

\begin{tabular}{|l|l|l|l|l|}
\hline & Intrinsic & & Adjusted & \\
\hline Fire index & $5.478,26$ & Most Serious & 340,72 & Most Serious \\
\hline Explosion confined Index & 4,55 & High I & 2,04 & Low \\
\hline Explosion in air index & 522,21 & A Lot High & 32,17 & Moderated \\
\hline General risk index & $668.949,26$ & Most Serious & $9.732,56$ & Most Serious \\
\hline
\end{tabular}

It appears clear that the control and the protection systems reduce the explosion indices (confined and in air). Vice versa, the fire index is always serious.

Moreover, the general adjusted index $\left(G^{\prime}\right)$ is very high.

\section{A.2.2 LPG storage categorisation}

It is necessary to compare the general index $G^{\prime}$ with the value ranges of Table $B$ (Table 2). In this case, the logical unit is associated to the D category.

This means that the logical unit must be considered of low and inadequate technological standards. At the same time, it represents a serious danger for the workers and the environmental quality.

So, in accordance with Italian Law, the Competent Authority may decide to restrict or to suspend the industrial activity until the operator improves the prevention and protection systems in order to lead the same logical unit almost to the $\mathrm{C}$ category. 


\section{References}

[1] Council Directive 96/82/EC of 9 December 1996 on the control of majoraccident hazards involving dangerous substances.

[2] D.P.R. 31/03/89 “Applicazione dell'art. 12 del DPR 17/05/88, n. 175, concernente rischi rilevanti connessi a determinate attività industriali".

[3] D.M. 15/05/1996 "Criteri di analisi e valutazione dei Rapporti di Sicurezza relativi ai depositi di GPL".

[4] D.L.vo 17/08/99, n. 334 “Attuazione della direttiva 96/82/CE relativa al controllo dei pericoli di incendi rilevanti connessi con determinate sostanze pericolose".

[5] D.M. 09/05/2001 "Requisiti minimi di sicurezza in materia di pianificazione urbanistica e territoriale per le zone interessate da stabilimenti a rischio di incidente rilevante".

[6] Ricci, P.F., Sagan, L.A. \& Whipple, C.G., Technological Risk Assessment, Risk evaluation and management, pp. 133-168, 1984.

[7] Chicken, J.C., Risk assessment for hazardous installations, Techniques for reliability and risk assessment, pp. 56-77, 1986.

[8] Gow, H.B.F. \& Kay, R.W., Emergency Planning for Industrial Hazards, Techniques for emergency plans, pp. 191-198, 1988.

[9] Torretta, V., Sicurezza e analisi di rischio di incidenti rilevanti, La normativa di settore, pp. 8-73, Adempimenti amministrativi, pp. 77-80, Analisi di rischio, pp. 121-168, Emergenza e compatibilità ambientale, p. 300, 2006.

[10] Marsili, G., La valutazione del rischio di area, La valutazione dei rischi industriali nella gestione del territorio, pp. 39-58, 2007.

[11] Rota, R. \& Nano, G., Introduzione alla affidabilità e sicurezza nell'industria di processo, La valutazione del rischio, pp. 271-284, 2007. 